\title{
O Papel da Recreação e do Lazer na Inclusão Social de Adolescentes
}

\author{
The Role of Recreation for Teenager's Social Inclusion
}

\author{
Virgílio Abrahão Junior*a; Julia Alejandra Pezuk abc \\ âniversidade Anhanguera São Paulo, Programa de Pós-Graduação Stricto Sensu em Ensino de Ciências e Saúde. SP, Brasil. \\ bUniversidade Anhanguera São Paulo, Programa de Pós-Graduação Stricto Sensu em Farmácia.SP, Brasil. \\ 'Universidade Anhanguera de São Paulo. Programa de Pós Graduação Stricto Sensu em Biotecnologia e Inovação em Saúde. SP, Brasil. \\ *E-mail: vikajunior@anhanguera.com
}

\begin{abstract}
Resumo
Atualmente no Brasil é possível observar uma parcela da população jovens, principalmente nas classes sociais mais baixas, sujeitos a situações que acarretam maior susceptibilidade para se envolver com drogas, prostituição, crimes, gravidez e doenças sexualmente transmissíveis. Diversos fatores psicossociais são necessários para que os adolescentes passem pela adolescência sem a necessidade deste tipo de envolvimentos. A recreação e o lazer podem ser usados como instrumento para facilitar a inclusão social e ao mercado de trabalho de jovens marginalizados. O impacto emocional positivo do uso da recreação e do lazer favorece o bem-estar e auxilia na inclusão social de adolescentes, e possibilitam o uso dessas ferramentas para serem explorados em eventos e atividades recreativas. Nesse contexto, o presente trabalho tem como objetivo mostrar a importância do desenvolvimento de projetos sobre recreação e o lazer para a inclusão social de jovens. Para isso é relatada a experiência com o Programa Social realizado na cidade de Guarulhos/SP intitulado Programa Oportunidade ao Jovem, que busca a qualificação profissional dos jovens da cidade que se encontram em situação de risco e pobreza, e que estão em geral excluídos da sociedade. Mostramos aqui que a inclusão social por meio de programas sociais usando atividades recreativas facilita a inserção social de jovens marginalizados e devem ser consideradas nas políticas públicas. Pois ainda permitem que adolescentes em situação econômica precária tenham a possibilidade de exercer uma profissão na área de recreação ao término dos cursos dos programas, impactando significativamente na vida desses jovens.
\end{abstract}

Palavras-chave: Programa Social. Agente de Recreação. Políticas Públicas.

\begin{abstract}
In Brazil it is possible to observe a portion of the young population, mainly in the lower social classes, who are subject to situations that cause greater susceptibility to get involved with drugs, prostitution, crimes, pregnancy and sexually transmitted diseases. Several psychosocial factors are necessary for adolescents to go through adolescence without the need for this type of involvement. Recreation can be used as an instrument to facilitate social inclusion and the labor market for marginalized youth. The positive emotional impact of recreation favors wellbeing and assists in the social inclusion of adolescents and enables the use of these tools to be explored in events and recreational activities. In this context, this paper aims to show the importance of developing projects on recreation for the social inclusion of young people. For this, the experience with the Social Program carried out in the city of Guarulhos / SP entitled Programa Oportunidade ao Jovem, which seeks the professional qualification of young people in the city who are at risk and poverty, and who are in general excluded from society, is reported. We show here that social inclusion through social programs using recreational activities facilitates the social insertion of marginalized youth and should be considered in public policies. Because they still allow adolescents in a precarious economic situation to have the possibility of exercising a profession in the area of recreation at the end of the program courses, significantly impacting the lives of these young people
\end{abstract}

Keywords: Social Program. Recreation Agent. Public Policy.

\section{Introdução}

A diversidade social existente entre as pessoas tem crescido de uma forma acelerada no Brasil, e em diversas situações de vulnerabilidade social os jovens são os mais afetados. Isso se deve não apenas ao fato de serem frequentemente influenciados de forma negativa, mas também pela falta de conhecimento e vivência com as diversas situações que acontece no dia a dia como ressaltam os autores Reis; Malta; Furtado (2018). Desta forma é possível perceber que o desemprego, a fome e a desigualdade representam um dos problemas sociais mais importante pois afetam significativamente a população jovem e as áreas nas quais é e será inserido.

Jovens marginalizados ou excluídos socialmente apresentam diversos entraves quando buscam entrar no mercado de trabalho, o que pode impactar na situação da vida adulta. Sabe-se que o mercado de trabalho requer do intercâmbio cotidiano de capacidade produtiva entre trabalhadores e empresas, que, juntamente com suas instituições, alocam recursos e renda entre si. Pode ser definido trabalho como um produto vendido pelos trabalhadores, sendo que são os empregadores que compram aquele produto pagando o mesmo através de salários, definindo assim o mercado de trabalho como o local onde acontecem tais transações. (OLIVEIRA; PICCININI, 2011). No entanto, devido as situações nas quais alguns jovens marginalizados estão imersos existe uma dificuldade real para que os mesmos sejam inseridos. Nesse contexto, Programas Sociais podem ser utilizados como ferramentas para captar jovens e capacitar os mesmo para mercado de trabalho. De fato, programa 
sociais podem garantir o treinamento dos jovens, além de impactar nas vulnerabilidades ou situações de risco como é o envolvimento com drogas, prostituição, crimes, gravidez e doenças sexualmente transmissíveis, muito frequente entre jovens marginalizados.

Nesse contexto surgiu o projeto de Lei ${ }^{\circ}$ 102/2004 dispõe sobre as parcerias da prefeitura de Guarulhos/SP com empresas e instituições que possam promover e gerar oportunidades para os jovens da cidade. Nesse sentido o inciso III do Artigo $2^{\circ}$ da Lei no 5.843 de 4 de Julho de 2002 (GUARULHOS, 2004) estabelece que as instituições particulares que estão no município de Guarulhos podem aderir ao compromisso social do Programa Oportunidade ao Jovem, proporcionando a estes sujeitos a chance de desenvolver as habilidades com recreação e aprimorá-los para a experiência profissional de trabalho voltado para a recreação, sendo que esses participantes do programa podem atuar como monitores ou agentes de recreação.

O projeto busca inserir o jovem ao mercado de trabalho, formando profissionais que terão seu lugar garantido junto as empresas participantes do projeto, com o compromisso de que a mão de obra do funcionário não será substituída pela do jovem participante do programa, nem mesmo caracterizando, ao jovem, vínculo empregatício. Desta forma o jovem, que vive em uma sociedade extremamente competitiva, onde a busca desenfreada por um trabalho requer que se tenha uma formação profissional diversificada, garante a possibilidade de atuar em seu meio de forma mais adequada e equilibrada. O principal objetivo desse projeto é proporcionar aos jovens melhores condições para a construção da sua cidadania, dando-lhes formação e capacitação que permita inseri-los no mundo do trabalho, de forma adequada à sua condição de pessoa em desenvolvimento conforme dita o ECA -Estatuto da Criança e do Adolescente (BRASIL, 1990). Nesse contexto, este estudo teve como objetivo relatar e discutir a experiência do Programa Oportunidade ao Jovem desenvolvido pela Prefeitura de Guarulhos que envolve a recreação e lazer, e explorar os efeitos que o mesmo tem nos jovens participantes.

\section{Material e Métodos}

Este estudo consiste em um relato de experiência e pesquisa bibliográfica sobre os tópicos relacionados ao projeto: recreação e inclusão social utilizando de políticas públicas. Os textos e conceitos são discutidos para análise acerca da ideia de profissionalizar jovens carentes como Agentes de Recreação. Este trabalho foi desenvolvido usando de elucidações conceituais de recreação e dos campos de atuação dos jovens treinados em recreação e lazer seguidas da reflexão sobre inclusão social. Primeiramente é relatada a experiência vivenciado no Programa Oportunidade ao Jovem gerenciado pela Secretaria do Trabalho e desenvolvida pela Prefeitura de Guarulhos. Em seguida é realizada uma revisão bibliográfica sobre recreação, exclusão social e políticas públicas a fim de contextualizar o assunto, o que permite uma análise do tema ao mesmo tempo que se faz uma discussão sobre os impactos na vida dos jovens participantes do programa.

\section{Resultados e Discussão}

\subsection{Relato da experiência}

O programa Oportunidade ao Jovem desenvolvido na cidade de Guarulhos, possui um curso formativo e modular que permite iniciar os jovens nas atividades de monitor, organizador e agente de atividades de recreação e lazer, propiciando meios para desenvolver habilidades específicas relacionadas com esse nicho de trabalho.

$\mathrm{O}$ curso busca que os participantes adquiram as seguintes competências específicas da formação (RIBEIRO, 2012):

- Educar para o divertimento e o lazer;

- Contribuir para que os indivíduos conheçam outras possibilidades de diversão, ampliando o leque de conhecimento de opções possíveis de serem buscadas;

- Contribuir para que o público entenda que os momentos de diversão se constituem em direitos sociais e devem ser motivos de uma vida digna;

- Contribuir para contrapor o enorme poder da televisão e dos meios de comunicação, tornando-se mais crítico perante o que é veiculado pelas emissoras;

- Ampliar a visão do indivíduo sobre a sociedade, já que ele vai ter acesso a novas formas de ver a realidade;

- Ser firme e comunicativo;

- Expressar-se com clareza, articulando bem as palavras, emitindo-as em alto e bom som;

- Entreter grupos de diferentes segmentos sociais e de diferentes faixas etárias, através de atividades recreativas;

- Diagnosticar e atender características e necessidades de cada grupo;

- Propor, desenvolver, executar e avaliar atividades de caráter recreativo e/ou sociocultural adequados ao diagnóstico, programação e execução de eventos socioculturais;

- Solucionar os problemas imprevistos na execução de atividades de forma a garantir um bom resultado final;

- Prevenir acidentes, aplicando normas de segurança nos locais e/ou atividades programadas.

- Zelar pela integridade dos recursos disponibilizados para realização das atividades recreativas programadas.

Para isso a organização curricular do Curso Agente de Recreação consistiu em três módulos divididos de acordo com as necessidades do curso e carga horária. Além das atividades próprias do Lazer e Recreação, os jovens também tiveram aulas de formação para a cidadania, além de aulas chamadas de estruturantes, como português, matemática, artes entre outras. O programa constou com o total de 420 horas incluindo todas as disciplinas de segunda a sexta por 04 horas diárias. Sendo que o Curso foi estruturado com base no referencial de aprendizagem com autonomia e do desenvolvimento de competências profissionais, entendidas como a "capacidade de 
mobilizar, articular e colocar em ação valores, conhecimentos e habilidades necessários ao desempenho eficiente e eficaz de atividades requeridas pela natureza do trabalho" que privilegia a prática pedagógica contextualizada, colocando o aluno diante de situações problemas que possibilitem o exercício contínuo da mobilização e articulação dos saberes necessários para a ação e a solução de questões inerentes à natureza do trabalho.

Todos os jovens participantes tinham entre 16 e 21 anos, eram provenientes de famílias residentes em Guarulhos com renda até 1,5 salário mínimo per capita e estavam matriculados no sistema público de educação, no Ensino Médio, regular ou EJA. Após o egresso do curso os jovens sentiam se preparados para atuar de forma a compreender as características, necessidades e potencialidades de grupos e comunidades, assim como para organizar, propor, executar programas e projetos de recreação e cultura. O projeto possibilitou que os jovens trabalhem em instituições de ensino participando em atividades recreativas e culturais, em empresas de lazer, e em qualquer nicho do campo relacionado com lazer e recreação em geral.

Por outro lado, a incorporação de tecnologias e práticas pedagógicas inovadoras desse curso, como o projeto de conclusão, mostrou que atende aos processos de produção da área, e às constantes transformações que lhe são impostas e às mudanças socioculturais relativas ao mundo do trabalho, pois propicia aos alunos a vivência de situações desafiadoras que levam a um maior envolvimento, instigando-os a decidir, opinar, debater e construir com autonomia o seu desenvolvimento profissional. Permitiu, ainda, a oportunidade de trabalho em equipe entre os jovens envolvidos no mesmo, assim como o exercício da ética, da responsabilidade social e da atitude empreendedora.

As situações de aprendizagem tiveram como eixo condutor um projeto de conclusão, que considerou contextos similares àqueles encontrados nas condições reais de trabalho, estimulando a participação ativa dos alunos na busca de soluções para os desafios que dele emergem. Estudo de casos, proposição de problemas, pesquisas em diferentes fontes, contato com empresas e especialistas da área, pesquisas, apresentação de seminários, visitas técnicas, atividades de campo, simulações de contextos e vivências em laboratório foram parte do repertório do trabalho por projeto deste curso. Na mediação dessas atividades, os docentes atuaram no sentido de possibilitar a identificação de problemas diversificados e desafiadores, orientando na busca de informações, estimulando o uso do raciocínio lógico e da criatividade, incentivando respostas inovadoras, criando estratégias que propiciem avanços, tendo sempre em vista que a competência é formada pela prática e que está se dá em situações concretas, impactando positivamente não apenas na formação mas nos participantes como seres humanos complexos, tendo impactos no cotidiano dos jovens envolvidos.

Esse curso possibilitou aos participantes a aprendizagem para trabalhar nas áreas de recreação e lazer como monitores ou recreadores. Durante o curso os jovens e adolesncentes foram treinados para atuar como recreadores, sendo capacitados para reunir pessoas, brincar e jogar com elas além de proporcionar o contato entre elas mesmas, proporcionando um ambiente e um momento onde haja integração, riso, dança, que se entretenham sem perder de vista suas responsabilidades a de estimulá-las a pensar sobre sua realidade. A formação desses jovens se dá de forma integral, articulando diversas dimensões do ser humano, incluindo eixos estruturantes a identidade e memória, a participação social, o mundo do trabalho, saúde e qualidade de vida, visitas técnicas; matemática instrumental, português instrumental, inclusão digital, e oficinas culturais implicou em impactos emocionais que impactara positivamente na vida desses jovens.

Nos últimos anos, houve uma mudança na forma de trabalhar e de se divertir, percebe-se que a sociedade está carente de lazer, o que acarreta numa diminuição da qualidade de vida (TEIXEIRA JUNIOR; SFERRA; BOTTCHER, 2012). O conhecimento sobre essa relação impacta atualmente na vida dos indivíduos, que tem tomado mais consciência sobre a importância, sendo também o lazer considerado nas empresas. E assim, ganha destaque o recreador, uma vez que o trabalhador em seu momento de lazer, necessita de pessoas capacitadas para orientá-los. Desta forma, o lazer e a recreação estão se tornando cada vez mais, itens importantíssimos dentro das funções, necessidades e direitos dos cidadãos. A partir da necessidade de se criar atividades e espaços para que as pessoas possam desfrutarem plenamente o seu tempo de livre, surgiu uma nova área de atuação profissional, os agentes de lazer (MENOIA, 2000).

Tem sido observado que atividades de lazer e recreação auxiliam a suprir as necessidades sociais de diversas parcelas da sociedade, tendo um impacto positivo na qualidade de vida das pessoas (BORGES; BRITO; MONTEIRO, 2020), o que implicaria num aumento na oferta de trabalho neste setor, onde os jovens formados poderiam ser inseridos. Atualmente a recreação abrange um crescente nicho de mercado de trabalho, que ainda é carente de mão de obra qualificada. Num estudo de 2012 foi mostrado que apenas metade dos profissionais da are ade recreação possuíam algum curso de capacitação (VITORIA et al., 2012), sendo então já apontada a necessidade de treinamento na área. A partir deste projeto, os jovens e adolescentes apresentariam capacidades para trabalhar na área de Lazer e Desenvolvimento Social. De fato, nos últimos anos o uso da recreação tem ganhado espaço, inclusive como ferramenta para a preparação e gerenciamento de emergências (PALMER, 2019). Dada a importância das atividades de lazer e recreação se faz necessária discutir o que se entende por recreação para poder ser explorado de forma correta como ferramenta de trabalho para a inclusão dos jovens que passaram pelo projeto social. 


\subsection{Recreação}

A palavra recreação vem do verbo latino recreare que significa reproduzir e/ou renovar. Desta forma a recreação deve ser entendida como uma atividade espontânea, natural, divertida, onde as pessoas buscam ações que melhorem sua qualidade de vida, satisfazendo suas necessidades físicas, psíquicas e mentais de forma prazerosa (YUKIT 1970; STREET; HAYLEY; CUTT, 2007). Nos dias atuais, o lazer e a recreação são requisitados em diversos locais, e não apenas em escolas durante as atividades formais, sendo comum incluir o lazer em diversos programas em navios, restaurantes, clubes, parques, condomínios, academias, entre outros espaços socialmente frequentados por pessoas de diversas faixas etárias. A recreação em geral é composta por jogos, brincadeiras, brinquedos, oficinas, onde o envolvimento do indivíduo acontece de forma gradual, intensa e espontaneamente. De acordo com Kishimoto (2011) a atividade recreativa está ligada aos jogos e as brincadeiras, onde se entende que o jogo deva ser considerado algo amplo cuja brincadeira faz parte do seu todo.

A recreação contribui na formação motora, intelectual e social, dando possibilidades para que as pessoas possam, através dela, expressar seus sentimentos de uma forma livres, espontâneos e natural, desenvolvendo assim, não somente aspectos motores como também cognitivos. Para Teixeira e Figueiredo (1970) e Cavallari e Zacharias (2000) a recreação é tudo o que distrai, diverte, fugindo ao comum daquilo que se faz habitualmente. Portanto, as práticas recreativas devem levar as pessoas a "estados psicológicos positivos", e deve ser realizada em um clima alegre, para que de maneira natural estimule a criatividade, o que quando usado em jovens e ados encetes pode causar um impacto na vida adulta. Cabe destacar, que o uso das atividades recreativas não é dirigido para obter resultados e ou benefícios comuns aos participantes além do lazer, pois deve ser considerada uma prática livre de cada interessado (CAVALLARI; ZACHARIAS, 2009). Porém, a recreação tem diversos benefícios para a formação pessoal, liberando o indivíduo das tensões diárias, podendo até resgatar valores necessários para auto realização. Adicionalmente, é sabido a prática de atividades recreativas é fundamental pois auxilia a atingir a quantidade de atividade física recomendada para manter a saúde (THORNTON et al., 2017).

$\mathrm{O}$ lazer faz parte do direito à cidadania, a própria Constituição Federal no capítulo II, artigo $6^{\circ}$ aponta: "São direitos sociais a educação, a saúde, a alimentação, o trabalho, a moradia, o transporte, o lazer, a segurança, a previdência social, a proteção à maternidade e à infância, a assistência aos desamparados, na forma desta Constituição" (BRASIL 1988). Tendo a Constituição Federal como regente aos nossos direitos não podemos negar aos jovens a oportunidade de transformação social através do lazer. De acordo com Montenegro (2011), o lazer é um contribuinte para uma sociedade mais justa e humana, com base nesta concepção é que acreditamos que o lazer possa ser a chave para inclusão dos jovens excluídos. Porém cabe destacar que não devemos ter o lazer como mercadoria e sim como ferramenta para causar a transformação social dos jovens excluídos.

De fato, a recreação pode ser entendida com duas funções básicas: a lúdica e a educativa. A função lúdica deve propiciar diversão e prazer, no entanto pode ocorrer desprazer neste momento, pois trata-se de uma escolha voluntária. Já a função educativa deve fazer a função de ensinar algo, qualquer coisa que complete o indivíduo. Tanto os jogos quanto as brincadeiras, podem ser aplicadas em qualquer faixa etária, ampliando mais ainda a atuação de um recreador (CAVALLARI; ZACHARIAS, 2009). Nesse contexto, o recreador é o mediador das atividades, tendo um papel fundamental na interação organizada entre as pessoas envolvidas nas dinâmicas. E ao mesmo tempo é o encarregado de elaborar e selecionar atividades de recreação e lazer buscando atrair a participação das pessoas. Assim, um dos requerimentos fundamentais para ser recreador é gostar de interagir com pessoas e culturas e por meio de ações didáticas, lúdicas e pedagógicas participar como um educador não formal, mostrando-se sensível e interpretando as expectativas do grupo para atingir os objetivos (RIBERO, 2012).

Adicionalmente se entende que a recreação também pode ser um instrumento de inclusão, não apenas para quem procura a recreação para se divertir, mas também para o profissional que a promove, no caso, o recreador. Tal ideia é compartilhada por Turino (2003), quando diz que a recreação pode ser um instrumento para inclusão no mercado de trabalho, principalmente para os jovens que participam de programas de recreação, uma vez que estes aprendem técnicas que podem ser usadas para explorar diversos nichos de trabalho com recreação. Para entender a repercussão que o uso de recreação tem nos jovens marginalizados acreditamos que é importante discutir o que é inclusão social e como a escola e a formação técnica profissional podem acarretar mudanças positivas para o desenvolvimento de indivíduos que estão à berlinda da sociedade civil.

\subsection{Inclusão e exclusão social}

A exclusão social como conceito político surgiu na Europa na década de 1980 em resposta às crescente divisões sociais resultantes das condições de mercado de trabalho e da inadequação de políticas sociais existentes nas diversas populações (ANACHE; SILVA, 2009). Segundo Costa e Carrion (2006) não existe consenso na definição dada por especialistas para o termo exclusão social, mas o termo inclusão social tem sido bastante veiculado e discutido em diversos setores sociais. Há vários conceitos, mas é aceito por unidade que a inclusão social introduz um novo horizonte para a sociedade, pois indica um processo de conquista dos direitos por parte dos mais diversos segmentos sociais.

A inclusão social vem ganhando força na sociedade e é aplicado em diversas áreas, principalmente, no que se refere 
as políticas sociais. Observa-se a inclusão social, na educação, saúde, e no mercado de trabalho, assim a inclusão social é entendida como o processo mais aperfeiçoado da convivência de alguém, tido como diferente, com os demais membros da sociedade, tidos como supostamente como iguais. Nesse sentido, para Holanda (1993) o termo "incluir" quer dizer: estar incluído ou compreendido, fazer parte. A melhor maneira de compreender a inclusão social é entendê-la no sentido prático, de fazer da inclusão social a vida real das famílias e das comunidades - como ponto de partida para a melhoria das condições de vida dos excluídos, prevendo a redução das desigualdades sociais.

A inclusão e a exclusão são descompromissos políticos, sendo que as políticas de atendimento não buscam modificar tal situação. Ambos termos são considerados como termos flexíveis, e vão mudando com a época e usabilidade (BORBA; LIMA, 2011). A exclusão é a consequência e contrapartida deste foco social, e tem sido considerado um instrumento de medida para descobrir e/ou medir as diversas análises que relacionam a violência com os direitos civis. $\mathrm{O}$ excluído não se afasta por si só, ele é afastado onde a condição de igualdade não é dada e muitas vezes o excluído é também explorado. Em geral os excluídos estão inteiramente interligados com os processos de inclusão, ou seja, os incluídos em processos sociais são os excluídos das camadas econômicas, sociais e culturais (PORTO, 2012). A exclusão social nada mais é do que a separação das camadas sociais, é o afastamento das classes, sendo que pode ser causada por diversos aspectos e fatores relacionados com as próprias condições de vida do indivíduo (BORBA; LIMA, 2011).

Ainclusão social representa uma conquista dos direitos para algumas parcelas da sociedade, ampliando as oportunidades para grupos desfavorecidos socialmente. A inclusão social pode ser vista como a forma de incluir na vida real das famílias e das comunidades mudanças que garantem melhoras nas condições de vida dos excluídos, acarretando redução das desigualdades entre os grupos e classes da nossa sociedade. $\mathrm{O}$ estudo de Gutierrez e Gonzalo (2019) mostra que a inclusão aboral de jovens marginalizados é determinada de acordo com o conhecimento, as atitudes, os hábitos, as competências e as capacitações, apontando a importância de estratégias sociais para essa parcela da população, sendo, portanto, fundamental a formação e capacitação para a inclusão.

O crescimento desordenado da sociedade gera questões sociais, que junto com os modelos econômicos e a falta de planejamento acarretam desigualdade, conduzindo os ínvidos a exclusão social. No Brasil, por exemplo, tratamos a exclusão social como restrição de renda, que devido a globalização impacta no acesso à internet e a troca de informação rápida. De fato, aqui no Brasil a condição social, econômica, ideológica e a cultural são os principais causadores de exclusão social, que já se tornou algo familiar, e pode ser considerada como o resultado de diversos problemas sociais, incluindo a urbanização, ensino, desenraizamento, desigualdade de renda e profissional, violência entre outros. Com essa visão pode se afirmar que a formação de profissionais é fundamental para conseguir uma sociedade mais igualitária, sendo que políticas públicas podem contribuir para garantir os direitos das minorias e dos mais susceptíveis, acarretando a inclusão social real desses indivíduos (SIQUEIRA; CASTRO 2017).

A inclusão social tem impactos positivos para a sociedade e traz bem-estar para as pessoas envolvidas, mas requer de ações como capacitações e investimentos que levam a quebrar paradigmas estabelecidos (GUERRA, 2012). De acordo com Oliveira (2008) para que exista real inclusão social para todos, em especial para os jovens que correspondem aos sujeitos desse estudo, é preciso mudar a forma de pensar e agir, respeitando as diferenças e o tempo de aprendizagem de cada um, o que nos faz crer acreditar que precisamos acreditar em uma possibilidade de estruturação personalizada na formação profissional destes jovens. Jovens e adolescentes podem ser incentivados ao crescimento e desenvolvimento pessoal e profissional, acarretando diminuição da exclusão social principalmente quando se usam de programas sociais para isso. De fato, diversos instrumentos têm sido explorados para promover a inclusão social entre jovens e adolescentes. Cabe destacar que os projetos que estimulam o uso da arte (TARRAGO; HABOWSKI; CONTI, 2017) e da dança (SILVA, 2016) tem impactos positivos no quesito inclusão social de jovens.

Um dos eixos fundamentais da inclusão social é a atividade profissional, sendo que para os adolescentes que hoje vivem à margem da sociedade, a participação em programas sociais pode, além de impactar no cotidiano, auxiliar os rapazes e as moças para terem uma vida profissional no futuro. No caso do programa de Oportunidade ao Jovem, permitem a formação como recreadores, impactando na sociedade carente de profissionais nessa área e garantindo nesses jovens uma atitude produtiva e participativa, levando a sua inclusão social.

Para que haja inclusão de fato, se faz necessário um trabalho em rede, ou ainda, um trabalho em equipe, que possa ser estendido aos órgãos particulares, como clubes, escolas, faculdades, universidade e escolas técnicas, que em conjunto com as políticas públicas possam desenvolver mecanismos de ação destes sujeitos como parte ativa e integrante reflexivo da sociedade. É interessante pensar que a instituição social que mais participa deste processo de inclusão é a escola, e muitas vezes é esta mesma escola que acaba excluindo os jovens, muitas vezes por não oferecer opções para uma real colocação no mercado de trabalho. No entanto, as instituições de educação formal ainda continuam sendo uma das principais responsáveis para a formação tendo impacto significativo na inserção social (MATISKEI, 2004). A escola pode contribuir para a formação profissional desses jovens, uma vez que pode ser considerada como um meio de contestação da ordem que domina a sociedade. Sendo que a limitação de recursos 
económicos pode ser superada através do emprego que está relacionado com a formação, diminuído assim a desigualdade social. Dessa forma, estabelecer projetos pedagógicos que auxiliam a dar conta da necessidade social devem ser pensadas em conjunto com as ações de políticas públicas. No entanto, há necessidade de complementar a formação de jovens e adolescentes com atividades extracurriculares para incrementar o conhecimento e evitar, sendo que as políticas públicas devem considerar esses aspectos.

\subsection{Programas sociais como políticas públicas}

De acordo com os dados da realidade brasileira e mundial, a inclusão deve ser não apenas um desejo, mas uma realidade que só será alcançada com grandes transformações sociais e políticas, assim se fazem necessário pensarmos em um projeto sobre ética e cidadania (LODI, 2003). Para Matiskei (2004), as políticas públicas que visam a inclusão devem ser capazes de atender as necessidades dos excluídos socialmente, não importando a origem, ou seja, tais projetos precisam dar conta de grupos com etnias diferentes, religiões, camadas sociais, opções sexuais, etc., e dessa forma tanto o Estado quanto os Municípios poderão dizer que contribuem para a inclusão social. De fato, o Estado/Município tem um papel fundamental para estabelecer programas que auxiliem os jovens que estão excluídos da sociedade gerando assim uma possibilidade de inclusão.

Existem diferentes vertentes que conceituam políticas públicas no Brasil. Uma delas define que:

Políticas públicas são conjuntos de programas, ações e atividades desenvolvidas pelo Estado diretamente ou indiretamente, com a participação de entes públicos ou privados, que visam assegurar determinado direito de cidadania, de forma difusa ou para determinado seguimento social, cultural, étnico ou econômico (BELINOVSK, 2013, p.12)

No entanto, Souza (2006) afirma que não existe a melhor ou única definição para políticas públicas, e aponta as mudanças histórica e social sobre os significados da temática. Nesse sentido, é possível afirmar que políticas públicas planejadas e focadas para jovens e adolescentes podem contribuir significativamente para a inserção social desses indivíduos tendo impactos positivos na sociedade.

Diversos fatores limitam a inserção social de jovens e adolescentes marginalizados por motivos socioeconômicos. $\mathrm{O}$ uso de drogas tem mostrado ter efeitos negativos em jovens e adolescente, podendo impactar no âmbito emocional, educacional e de entretenimento e lazer (MENEZES; PEREIRA, 2019). O uso de estratégias que acarretem desenvolvimento positivo de jovens e adolescentes tem sido o objetivo de diversos programas e deve ser considerado nas políticas públicas. Resultados positivos têm sido observado com o uso da música, que além de proporcionarem acesso à cultura e educação permitem uma vida mais saudável e abrangente (NETTO; SANTOS; SANTOS, 2019), ao igual que outros projetos relacionados com arte e dança (TARRAGO; HABOWSKI; CONTI, 2017; SILVA, 2016). Sabendo disso, a formação destes profissionais na área do lazer especialmente é fundamental e deve ser considerada nas políticas públicas, visando a consolidação da legalidade do lazer e da recreação para a inclusão social.

Visando os jovens como profissionais em recreação precisamos ter mais programas sociais como "cursos" gratuitos voltados como políticas públicas, assim acreditamos que uma formação pautada no senso comum e tecnicista ajuda a quebrar o paradigma tradicional, e enfatiza tanto no docente como discente como sujeitos do processo. Nesse sentido, Montenegro (2011) nos traz que esses profissionais devem ter um vasto conhecimento entre faixas etárias, conceitos culturais, sociais e biológico. Políticas públicas são fundamentais para integração laboral de jovens levando à inserção social, através da aprendizagem profissional (SILVA, 2017).

\section{Conclusão}

A melhor maneira de compreender a inclusão social é entendê-la no sentido prático de fazer da inclusão social a vida real das famílias e das comunidades, como ponto de partida para a melhoria das condições de vida dos excluídos, prevendo a redução das desigualdades sociais. Jovens de baixa renda estão vivendo a berlinda da sociedade, próximos da violência que acomete muitas famílias incluindo envolvimento com diversos tipos de drogas, prostituições, gravidez, aborto e com o crime em geral. A partir desta parte sensível da sociedade, a prefeitura de Guarulhos junto com algumas instituições particulares desenvolveu projetos onde jovens marginalizados foram incentivados a trocar as ruas pelas salas de aula, a incerteza do mundo do trabalho pela capacitação de uma profissão, podendo assim ter uma formação cidadã plena e ser capacitado para exercer uma profissão.

O programa Oportunidade ao Jovem da cidade de Guarulhos/SP representa uma oportunidade que favorece a capacitação de jovens em situação de vulnerabilidade social podendo o mesmo ser protagonista de sua própria vida, o programa fornece auxílio em aulas instrumentais de português e matemática, oficinas de teatro e circo tendo um impacto positivo na vida dos jovens envolvidos. Todo o conteúdo do projeto está voltado e tem efeito em auxiliar os jovens marginalizados para se tornarem agentes de recreação e lazer e assim poder ter a possibilidade de atuar como profissionais capacitados, integrando-se a sociedade de forma ativa e produtiva. A participação dos jovens em programas sociais sobre recreação e lazer além de ter um impacto social possibilita a utilizar das estratégias utilizadas como ferramenta de trabalho permitindo sua inserção na área de recreação, que atualmente está em alta, apontando a importância de políticas públicas que garantam o uso de lazer e recreação na formação de jovens adolescentes. 


\section{Referências}

BELINOVSKI, A.C. Politica de Assistência Social: avanços e possibilidades no Centro de Referência Especializado de Assistência (CREAS) do município de Telêmaco Borba/PR. Curitiba: Universidade Tecnológica Federal do Paraná, 2013

BORBA, A.A.; LIMA, H.M. Exclusão e inclusão social nas sociedades modernas: um olhar sobre a situação em Portugal e na União Europeia. Serv. Soc. Soc., n.106, p.219-240, 2011.

BORGES, R.M.; BRITO, C.M.D.; MONTEIRO, C.F. Saúde, lazer e envelhecimento: uma análise sobre a brincadeira de dança de roda das Meninas de Sinhá. Interface, v.24, e190279, 2020. doi: http://dx.doi.org/10.1590/interface.190279

BRASIL, Presidência da República Casa Civil Subchefia para Assuntos Jurídicos. Constituição da República Federativa do Brasil de 1988. Disponível em: http://www.planalto.gov.br/ ccivil_03/Constituicao/Constituicao.htm.

BRASIL, Presidência da República Casa Civil Subchefia para Assuntos Jurídicos. Subchefia para Assuntos Jurídicos. Lei ${ }^{\circ}$ 8.069, de 13 de julho 1990. Disponível em: http:/www.planalto. gov.br/ccivil_03/leis/18069compilado.htm

CAVALLARI, V.R.; ZACHARIAS, V. Trabalhando com a recreação. São Paulo: Ícone, 2009.

COSTA, P.A.; CARRION, R.S.M. A difícil tentativa de aportar racionalidade a iniciativas populares de trabalho e produção coletiva estruturadas em moldes associativos: estudo de caso do município de Cachoeirinha. Redes, v.11, n.2, p.299-317, 2006.

GUARULHOS. Projeto de Lei No 102/2004. 2004. Disponível em https://www.guarulhos.sp.gov.br/06_prefeitura/leis/projetos_ download/04PL0102.pdf.

GUERRA, P. Da exclusão social à inclusão social: eixos de uma mudança paradigmática. Rev. Angolana Soc., v.10, p. 91-110, 2012. doi: https://doi.org/10.4000/ras.257

GUTIERREZ, A.B.; GONZALO, A. Estrategias de inserción laboral y capital social. Un estudio sobre jóvenes de clases populares en Córdoba, Argentina. Última Década, v.27, n.51, p.160-191, 2019. doi: http://dx.doi.org/10.4067/S071822362019000100160

HOlandA, A.B. Dicionário Prático da Língua Portuguesa. Aurélio. Rio de Janeiro: Nova Fronteira, 1993.

KISHIMOTO, T.M. (Org.). Jogo, brinquedo, brincadeira e a educação. São Paulo: Cortez, 2011.

LODI, L.H. (Org.). Ética e cidadania: construindo valores na escola e na sociedade. Brasília: MEC, 2003.

ANACHE, A.A.; SILVA, I.R. Educação inclusiva: experiências profissionais em psicologia. In: ACHADO, A.M.; ALMEIDA, I.; SARAIVA, L.F.O.M. Rupturas necessárias para uma prática Inclusiva. Brasília: Conselho Federal de Psicologia, 2009. p.2136.

MATISKEI, A.C.R.M. Políticas de inclusão educacional: desafios e perspectivas. Rev. Educar, v.1, n.23, p.185-208, 2004. doi: https://doi.org/10.1590/0104-4060.338.

MENEZES, A.L, PEREIRA, A.R. Desempenho ocupacional de adolescentes usuárias de drogas. Cad. Bras. Ter. Ocupac., v.27 n.4, p.754-764, 2019. doi: https://doi.org/10.4322/2526-8910. ctoao1885.

MENOIA, T.R.M. Lazer: história, conceitos e definições. Campinas: UNICAMP, 2000

MONTENEGRO, G.M. Políticas públicas do lazer: um enfoque na formação. EFDeportes.com, v.16, n.156, 2011.
NETTO, I.M.C, SANTOS, G.J, SANTOS, L.M.M. Grupo musical como contexto para promoção do desenvolvimento positivo de adolescentes. Interface, v. 24, e190367, 2019. doi: https://doi. org/10.1590/interface.190367

OLIVEIRA, A.L.C.S. Inclusão: direito de todos. Inclusão Social, v.3, n.1, p.43-47, 2008.

OLIVEIRA, S.R.; PICCININI, V. C. Mercado de trabalho: múltiplos (des) entendimentos. Rev. Adm. Pública, v.45, n.5, p.1517-1538, 2011. doi http://dx.doi.org/10.1590/S003476122011000500012.

PALMER L. Emergency preparedness in Canada: the role of recreation. J. Emerg Manag., v.17, n.5, p.371-379, 2019. doi: https://doi.org/10.5055/jem.2019.0432

PORTO, M.S.G. Tempo Social. A violência entre a inclusão e a exclusão social. Rev. Sociol. USP, 2012. doi: https://doi. org/10.1590/S0103-20702000000100010

REIS, A.A.C.; MALTA, D.C.; FURTADO, L.A.C. Desafios para as políticas públicas voltadas à adolescência e juventude a partir da Pesquisa Nacional de Saúde do Escolar (PeNSE). Ciênc. Saúde Coletiva, v.23, n.9, p.2879-2890, 2018. doi: https://doi. org/10.1590/1413-81232018239.14432018.

RIBERO, C.G. Monitor em recreação. Curitiba: IFPR, 2012

SILVA, E.L.A Inclusão social de jovens em projetos sociais relacionados à dança: uma breve revisão. Essentia, v.17, 24-34, 2016.

SILVA, P. F. O impacto socioeconômico da implementação do Programa Jovem Aprendiz a partir da inclusão laboral dos jovens aprendizes atendidos pelo instituto federal de Brasília. Brasília. Rev. UIIPS v.5, n.3, p. 54-65, 2017.

SIQUEIRA, D.P.; CASTRO, L.R. Minorias e grupos Vulneráveis: A questão terminológica como fator preponderante para uma real inclusão social. Rev. Direitos Soc. Políticas Públicas, v.5, n.1, 2017. doi: http://dx.doi.org/10.25245/rdspp.v5i1.219

SOUZA, C. Políticas públicas: uma revisão da literatura. Sociologias, v. 8, n.16, 2006.

STREET, G; HAYLEY CUTT, R.J. The relationship between organised physical recreation and mental health. Health Promot $J$ Austr., v.18, n3, p.236-239, 2007.

TARRAGÔ, L.S.; HABOWSKI, A.C.; CONTI, E. A inclusão social por meio das artes: possibilidades e limites na educação. Rev. Gestão Universitária, 2017.

TEIXEIRA JÚNIOR, M.A.B.; SFERRA, L.F.B.; BOTTCHER, L.B. A importância do lazer para a qualidade de vida do trabalhador. Rev. Conexão Electr., n.9, p.1-15, 2012.

TEIXEIRA, M.S.; FIGUEIREDO, J.S. Manual teórico-prático recreação para todos. São Paulo: Obelisco, 1970.

THORNTON, C.M. et al. Relation of adolescents' physical activity to after-school recreation environment. J. Phys Act. Health., v.14, n 5, p 382-388, 2017. doi: 10.1123/jpah.2016-0365

TURINO, C. Lazer nos programas sociais. São Paulo: Anita, 2003.

VITORIA, E.M. et al. Perfil dos profissionais atuantes na área de recreação hoteleira do município de Foz do Iguaçu, PR. EFDeportes.com, v.17, n.168, 2012.

YUKIC, T.S. Fundamentals of recreation. New York: Harpers \& Row, 1970. 